\title{
Co-integration of acoustic simulation software and GIS for speech intelligibility analysis in complex multi-source acoustic environments.
}

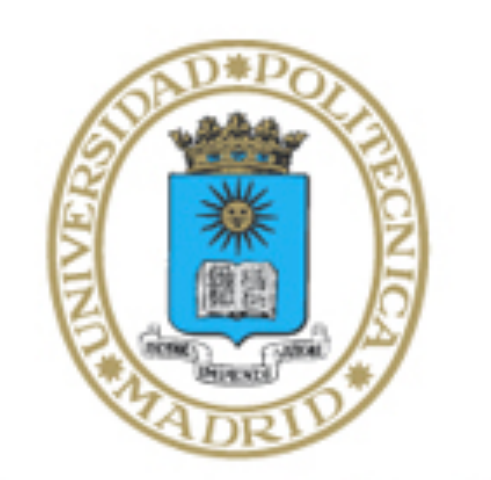

POLITÉCNICA
Application to Toledo's Cathedral

Antonio Pedrero, Luis Iglesias, Rogelio Ruiz and Cesar Díaz

Grupo de Investigación en Acústica Arquitectónica, Technical University of Madrid,

Speech intelligibility in multi-speaker environments

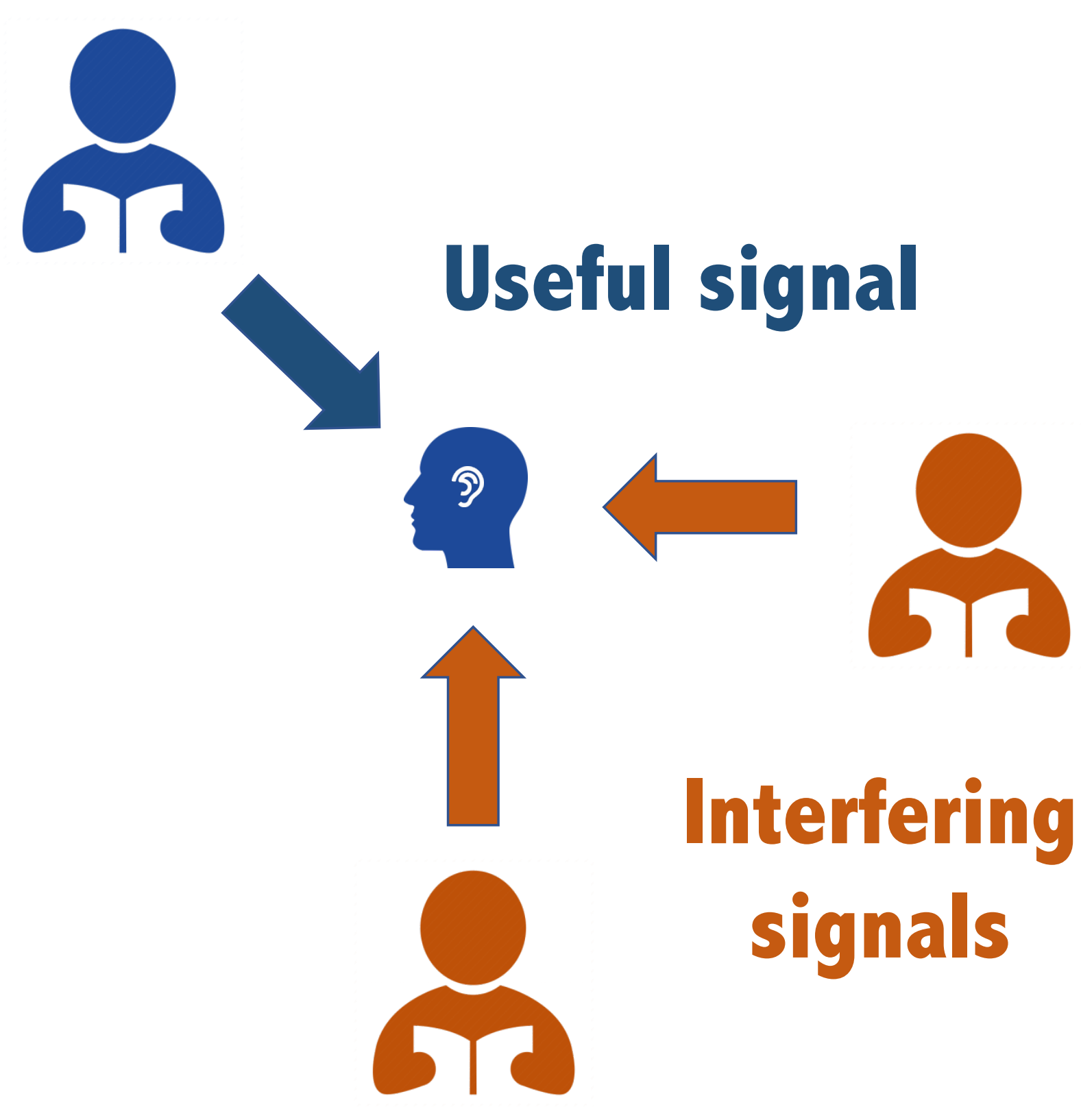

\section{Assessment criteria}

- Privacy distance, $r_{p}$ : distance from speaker where the speech transmission index falls below 0,20 .

- Distraction distance, $r_{D}$ : distance from speaker where the speech transmission index falls below 0,50 .

\begin{tabular}{|c|c|c|}
\hline Condition & Distance from target speaker & Distance from interf. speaker \\
\hline Optimal & $\mathrm{d}_{\mathrm{ts}}<\mathrm{r}_{\mathrm{D}}$ & $\mathrm{d}_{\mathrm{is}}>\mathrm{r}_{\mathrm{p}}$ \\
\hline Acceptable & $\mathrm{d}_{\mathrm{ts}}<\mathrm{r}_{\mathrm{p}}$ & $\mathrm{d}_{\mathrm{is}}>\mathrm{r}_{\mathrm{p}}$ \\
\hline Unacceptable & Any distance & $\mathrm{d}_{\mathrm{is}}<\mathrm{r}_{\mathrm{p}}$ \\
\hline
\end{tabular}

\section{Methodology}

Limitations of acoustic simulation programs

- For the STI calculation, a single background noise value is set for the entire room.

- Normally, they do not allow differentiation between useful and interfering sound sources

Advantages of GIS programs

- Possibility of automating complex calculations with the data of each of the raster points.

- Multiple geographical calculation options (areas, distances, etc.).
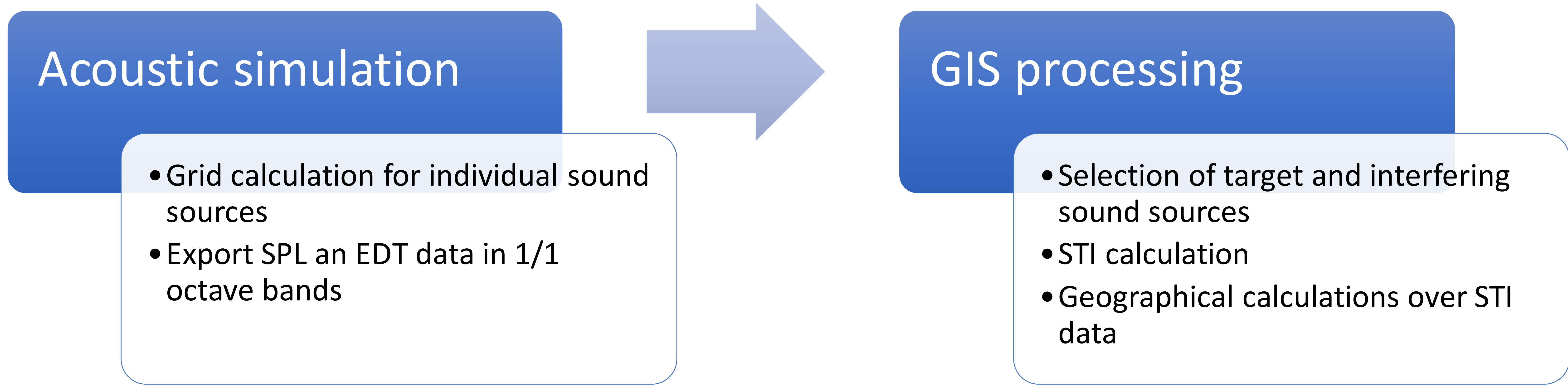

\section{Case Study}

Study of the simultaneity of liturgical activities in the Cathedral of Toledo (S XVI)

According to historical documentation, 30,000 annual masses (100 masses / day)

Analysis of possible activity at 08:00 am


\begin{tabular}{|l|c|}
\hline \multicolumn{2}{|c|}{ Statistical values for STI $=0,2$} \\
\hline Minimum distance & $6,6 \mathrm{~m}$ \\
\hline Maximum distance & $21,4 \mathrm{~m}$ \\
\hline Average distance & $13,6 \mathrm{~m}$ \\
\hline Standard deviation & $4,8 \mathrm{~m}$ \\
\hline \multicolumn{2}{|c|}{ Statistical values for STI $=0,5$} \\
\hline Minimum distance & $2,0 \mathrm{~m}$ \\
\hline Maximum distance & $6,4 \mathrm{~m}$ \\
\hline Average distance & $5,0 \mathrm{~m}$ \\
\hline Standard deviation & $1,3 \mathrm{~m}$ \\
\hline
\end{tabular}

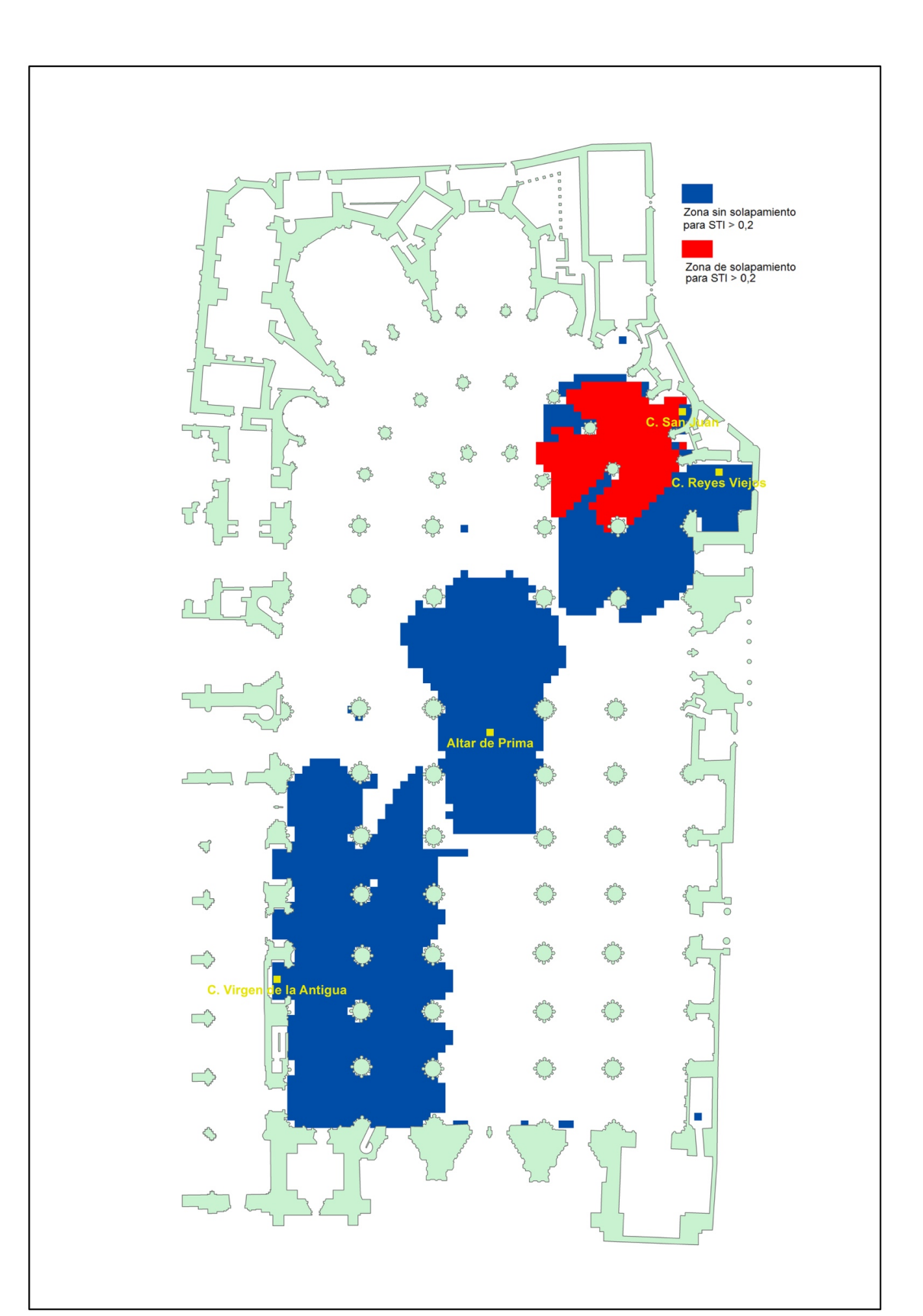

